\title{
RELIGIOSITAS TRADISI JAWA ISLAM DALAM SENI BATIK
}

\author{
Naomi Kawasaki \\ Universitas Sebelas Maret Surakarta (UNS) \\ Jl. Ir. Sutami No. 36 A (+62-271) 646624 Surakarta 57126 \\ E-mail: naomitti817@ybb.ne.jp \\ HP. +62-87836036847
}

\begin{abstract}
This paper discusses the contents of religious values in batik. Classical batik motifs interpreted as decoration that was created in ancient times. The ornament is not something that only visually beautiful, but also given a meaning that is closely related to Javanese philosophy of human life. This means that the Java man, the beauty of decorative batik is more understood as an attempt to provide breath and soul of traditional clothing. In the life cycle of Java people, Solo batik cloth used in the event-related customs Javanese ritual called slametan (salvation). Slametan ceremony is a socio-religious activities of the Java community.
\end{abstract}

Abstrak: Tulisan ini membahas tentang muatan nilai relijius dalam batik. Motif klasik batik diartikan sebagai ragam hias batik yang diciptakan pada zaman dahulu. Ragam hias tersebut bukan sesuatu yang hanya indah secara visual, tetapi juga sesuatu yang diberi makna yang erat hubungannya dengan falsafah hidup manusia Jawa. Ini berarti bahwa bagi manusia Jawa, keindahan ragam hias batik lebih dimaknai sebagai upaya untuk memberikan nafas dan jiwa dari busana tradisional. Dalam daur hidup manusia Jawa, kain batik Solo digunakan pada acara yang berhubungan dengan adat-istiadat Jawa yang disebut upacara slametan (selamatan). Upacara slametan merupakan kegiatan sosio-religius masyarakat Jawa.

Kata Kunci: Batik, Jawa, Solo, Adiluhung, Slametan.

\section{A. Pendahuluan}

Batik menjadi salah satu warisan adiluhung budaya Jawa. Keunikan dan kekhasan motif dan ragam hias Batik Solo yang sarat nilai filosofis menjadikannya sebagai warisan budaya yang perlu dijaga dan dikembangkan. Gagasan serupa pernah diutarkan oleh mantan Walikota Surakarta, Joko Widodo, dan mantan Duta Besar Indonesia untuk Jepang dalam kutipan berikut. 
"Batik adalah kerajinan yang mengandung filosofi, memiliki karakter, dan nilai seni, serta menjadi bagian dari budaya Indonesia sejak lama. Sebagai ikon budaya, batik merupakan lokal genius yang mengandung nilai sejarah yang sangat tinggi. Semoga batik akan menjadi warisan sejarah yang mampu menjawab modernisasi dan terjaga eksistensi tradisinya" (Widodo, dalam Atmojo, 2008: 6).

Pengakuan ini tidak hanya datang dari masyarakat Solo sebagai pelaku budaya dan/atau pemerintah daerah dan pusat sebagai pemangku kekuasaan negara, tetapi juga dunia internasional. Oleh karena itu, dunia internasional yang telah menjadi bagian integral dari budaya tersebut merasa berkepentingan untuk ikut menjaga dan mengembangkan batik. Hal ini terbukti dengan terpilihnya batik sebagai salah satu warisan budaya takbenda pada tanggal 2 Oktober 2009 oleh UNESCO.

Batik Solo begitu terkait dengan kehidupan manusia Jawa sehingga tidak dapat terpisah dari kehidupan masyarakat Jawa, terutama kehidupan dan/atau kegiatan di dalam Keraton Kasunanan Surakarta. Sebagaimana pernyataan Paku Buwono IX, dalam Pujiyanto (2010: 13), "Nyandhang panganggo hiku dadyo seonohamemangun wataking manungso jobo-jobo (memakai busana dan perlengkapannya itu menandakan watak lahir dan batin dari si Pemakai)".

Solo sebagai pusat Kerajaan Mataram Jawa (Kasunanan Surakarta) eksis dengan segala tradisi serta adat-istiadat keratonnya. Keraton bukan hanya sekadar kediaman raja-raja, melainkan juga merupakan pusat pemerintahan, agama, dan kebudayaan. Keadaan ini mempengaruhi juga produksi ragam hias, tata warna, dan pemakaiannya (Djoemena, 1990a: 10). Batik tradisional Solo lazimnya dipenuhi dengan motif klasik dan digunakan pada acara yang erat hubungannya dengan adat-istiadat manusia Jawa (Widiastuti, 1993: 5). Motif klasik batik diartikan sebagai ragam hias batik yang diciptakan pada zaman dahulu. Ragam hias tersebut bukan sesuatu yang hanya indah secara visual, tetapi juga sesuatu yang diberi makna yang erat hubungannya dengan falsafah hidup manusia Jawa. Hal ini berarti bahwa bagi manusia Jawa, keindahan ragam hias batik lebih dimaknai sebagai upaya untuk memberikan nafas dan jiwa dari busana tradisional. Implementasi keindahan ragam hias batik ini akhirnya menjadi busana tradisional Jawa yang sekaligus menjadi simbol kosmologi, dasar orientasi diri, dan cermin sikap hidup. Ilustrasi ini tampaknya dapat dijadikan pijakan argumentasi bahwa apabila makna filosofis dan proses pembuatan Batik Solo melalui proses pertimbangan yang rumit dan matang, maka Batik Solo dapat dianggap sebagai wujud budaya Jawa yang agung (adiluhung). 
Keraton Kasunanan Surakarta sebagai penerus Dinasti Mataram merupakan pemangku kebudayaan Jawa yang sekaligus pusat magis terbesar budaya Jawa. Oleh karenanya, sudah sepantasnya seni batik berkembang pesat di Jawa dan menjadikan Solo sebagai salah satu pusat batik di Jawa. Eksistensi Solo sebagai salah satu pusat batik di Jawa ini diperkuat dengan keberadaan beberapa kampung batik yang hingga saat ini tetap bertahan. Dua kampung batik di Solo yang menjaga dan mengembangkan batik sebagai warisan budaya Jawa, yaitu Kampung Batik Kauman dan Laweyan. Secara visual, dua kampung batik ini menyiratkan pernah mengalami masa kejayaan. Kejayaan ini merupakan bukti bahwa warga kedua kampung ini pernah berhasil meningkatkan kesejahteraan melalui usaha batik yang pada zamannya mampu memenuhi tunt utan kebutuhan busana tradisional Jawa.

Tulisan ini mengungkap tentang Batik Solo yang senyatanya memiliki nilai adiluhung dalam khazanah budaya Jawa. Tidak dipungkiri bahwa busana tradisional Batik Solo dapat dimaknai sebagai batik tradisional Solo yang dipakai, baik dalam kehidupan sehari-hari maupun dalam kegiatan adat manusia Jawa yang berkaitan dengan daur hidupnya secara spiritual. Makna tersebut sudah mengalami perubahan sejalan dengan derasnya arus modernisasi yang ditandai dengan semakin canggihnya media informasi dan tumbuh suburnya budaya instan. Dalam hal ini, usaha untuk reformulasi pemahaman Batik Solo yang memiliki nilai religius perlu untuk dicermati secara mendalam.

\section{B. Batik Solo: Warisan Adiluhung Budaya Jawa Islam}

Inagaki (1976: 12-13) mengatakan bahwa pada awalnya teknik membatik merupakan salah satu seni kerajinan khusus putri-putri keraton. Hal ini karena bahan-bahan yang digunakan untuk membatik sulit diperoleh. Warna batik pun belum begitu berkembang, yang ada hanyalah kain putih yang dicelup dengan warna biru (indigo). Dalam perkembangan, sekitar abad ke-13, warna merah dan kuning yang berasal dari kembang Pulu mulai dipakai. Selanjutnya, pada akhir abad ke-16, kegiatan membatik mulai tersebar dalam masyarakat Jawa, bukan hanya milik putri-putri keraton, dan sekitar awal abad ke-17, warna soga seperti yang dapat terlihat dalam perwujudan Batik Solo pada umumnya baru ditemukan.

Tirta (2009: 17) mengungkapkan bahwa istilah "batik" yang dalam Bahasa Jawa bathik berasal dari kata Jawa Kuno "titi" yang berarti "dengan teliti atau cermat", atau "titik" yang berarti "diberi tanda titik". Pendapat ini diperkuat Wastraprema (dalam Widiastuti, 1993: 14) yang menghubungkan kata bathik dengan bahasa Jawa krama inggil, yaitu seratan, sebagai berikut. 
Seratan dalam bahasa krama inggil (bahasa halus) berarti tulisan yang dihubungkan dengan pekerjaan membatik, di mana hasilnya disebut batik tulis. Adapun "tik" atau "tes" dalam bahasa ngoko (awam) artinya menetes, menitik. Hal ini dihubungkan dengan menitikkan lilin cair dari carat canting yang menimbulkan susunan titik, membentuk goresan lilin. "Mbat" dalam bahasa Jawa ngoko diambil dari kata "nyambat" yang berarti mengerjakan sesuatu, dan "thik" dari kata "nithik" berarti sesuatu yang halus, kecil, lembut, rumit. Gabungan kedua kata ini, "mbathik", berarti mengerjakan sesuatu yang lembut, kecil dan rumit.

Sentalu (dalam Tozu (Ed.), 2007: 196-204), menjelaskan bahwa secara historis, istilah "batik" dapat ditemukan dalam tiga buah karya sastra Jawa, yaitu 1) sebuah naskah tua yang ditulis di atas daun lontar yang ditemukan di Galuh yang terletak bagian selatan kota Cirebon, pada tahun 1520, menyebutkan bahwa arti kata "batik" berasal dari bahasa Jawa yaitu tik (mengambarkan titik), tetes (tetes), atau seratan (hasil karya); 2) Babad Sengkala pada tahun 1633; dan 3) Pandji Djaja Lengkala pada tahun 1770. Sebelum istilah batik ini dikenal, batik lazim dikatakan "tulis" atau "lukis". Dalam perkembangan, terdapat dua sebutan untuk kain batik dalam bahasa Jawa, yaitu jarit batik (dalam bahasa Jawa ngoko) dan sinjang seratan (dalam Bahasa Jawa krama) (Pujiyanto, 2010: 16).

Batik keraton diciptakan dan dikembangkan dengan dilandasi falsafah kebudayaan Jawa yang mengacu pada nilai-nilai spritual. Dengan kata lain, batik keraton adalah sebuah ungkapan falsafah hidup manusia Jawa (Yayasan Harapan Kita/BP 3 TMII, 1997: 5). Oleh karenanya, batik keraton atau Batik Solo merupakan salah satu warisan adiluhung budaya Jawa yang berpusat dan dikembangkan di Solo.

\section{Penggunaan Batik Solo}

Batik Solo lebih sering dipakai sebagai busana adat masyarakat Jawa, terutama di lingkungan Keraton Solo dan Pura Mangkunegaran, baik untuk sehari-hari maupun acara-acara khusus. Pada awalnya, pengunaan kain batik lazim dipakai sebagai busana yang menut upi tubuh bagian bawah. Kegunaan batik, secara tradisi, dapat dijadikan untuk 5 bagian berbusana, yakni sebagai berikut (Yayasan Harapan Kita/BP 3 TMII, 1997: 36-39).

a. Kain panjang, yaitu kain yang dipakai sebagai penut up tubuh dari bagian pinggang sampai mata kaki. Ketika dipakai oleh wanita, kain panjang dililitkan ke bagian badan mulai dari arah kiri ke kanan, sedangkan apabila dikenakan oleh pria biasanya dililitkan ke arah sebaliknya, yaitu dari arah 
kanan ke kiri. Kain panjang dianggap sebagai busana yang lebih resmi daripada sarung.

b. Sarung, yaitu kain yang dijahitkan antarpinggir kain hingga berbentuk seperti silinder. Menutupi tubuh dari bagian pinggang sampai mata kaki dengan cara memasuki tubuh dalam bentuk silinder tersebut seperti baju rok. Sarung pada mulanya merupakan pakaian daerah pesisir.

c. Selendang, yaitu kain yang digunakan pada bahu, sering dipakai bersama dengan kain panjang sebagai pelengkap busana secara resmi. Selendang kadang disebut juga dengan kain gendongan, yaitu kain yang digunakan untuk menggendong bayi atau membawa barang oleh wanita.

d. Ikat kepala, yaitu kain yang diikatkan pada kepala yang digunakan hanya oleh pria.

e. Kemben, yaitu kain penutup badan bagian dada yang mengelilingi bagian atas badan.

\section{Batik Solo sebagai Ekspresi Kosmologi Jawa Islam}

Menurut Tirta (2009: 49), seni batik adalah salah satu dari beberapa 'seni keraton', yang mencakup antara lain wayang, tari-tarian, gamelan, dan puisi. Seni keraton tersebut merupakan kepanjangan sebuah falsafah yang dilandasi disiplin spiritual, bahkan berbagai kesenian itu mempunyai landasan falsafah yang sama. Disiplin spiritual tersebut, misalnya pengendalian diri, tata cara (etika), dan keselarasan (hormoni) yang bermakna sangat penting bagi manusia Jawa. Oleh karenanya, Batik Solo tidak dapat dilepaskan konteks budaya Jawa dan Keraton Solo sebagai pemangku kebudayaan Jawa yang sekaligus sebagai pusat kosmologi manusia Jawa.

Batik Solo termasuk yang tumbuh dan berkembang di atas dasar-dasar falsafah kebudayaan Jawa mengacu pada nilai-nilai spiritual dan pemurnian diri, serta memandang manusia dalam konteks harmoni semesta alam yang tertib, serasi, dan seimbang (harmonis). Harjonagoro (2007: 190, 194), mengungkapkan falsafah yang tercermin dalam perwujudan kain batik sebagai asal mulaning dumadi dan manunggaling kawula Gusti.

Kanjeng Susuhunan Pakubuwono IX mengatakan, "memakai busana dan perlengkapannya itu menandakan watak lahir dan batin dari si pemakai" (Pujiyanto, 2010: 13). Ini berarti bahwa kain Batik Solo dimaknai bukan hanya sebagai penutup tubuh manusia (busana), melainkan sesuatu yang merupakan pantulan pandangan hidup manusia Jawa yang sarat dengan pemahaman manusia atas kosmosnya. 
Ajaran Islam sangat menekankan manusia untuk menutup aurat agar senantiasa selamat di dunia dan akhirat, seperti yang tertera dalam ayat berikut ini.

"Dan katakanlah kepada wanita-wanita yang beriman: 'Hendaklah mereka menahan pandangannya dan memelihara kemaluannya dan janganlah mereka menampakkan perhiasannya kecuali yang biasa tampak dari padanya. Dan hendaklah mereka menutupkan khumurnya ke dadanya..."”(Q.S.24: 31).

Dari ayat itu, dipahami bahwa pakaian (baca: batik) tidak hanya bernilai seni saja, tetapi sebagai penutup aurat. Dalam keadaan tertentu, batik sering dipakai untuk beribadah. Seiring kehadiran para wali di tanah Jawa, beberapa ornamen dari batik dibuat dengan perpaduan antara nilai-nilai Islami dan nilai luhur orang Jawa.

Dalam pandangan hidup manusia Jawa, terdapat dua konsep dalam ruang kesadarannya atas kosmos (universe) yang mengelilingi dirinya, yang pertama mikrokosmos yang disebut "jagad cilik (alit)" dan, yang kedua makrokosmos yang disebut "jagad gede" (Pitana, 2001: 19). Jagad cilik adalah perwujudan dari diri manusia, sedangkan jagad gede refleksi dari jagad raya yaitu sesuatu yang ada di luar dirinya. De Johng (1984: 14) mengungkapkan bahwa pandangan hidup manusia Jawa dari sisi antropologinya, seperti berikut:

"Manusia terdiri at as bagian batiniah dan lahiriah. Bagian batiniah ialah rohnya, sukma atau pribadinya. Bagian ini mempunyai asal-unsul dan tabiat Ilahi. Maka dari itu, batin merupakan kenyataan yang sejati. Bagian lahir dari diri manusia ialah badannya dengan segala hawa nafsu dan daya-daya rohani. Badan inilah merupakan wilayah kerajaan rohnya. Itulah dunia yang harus dikuasainya. Maka dari itu, badan seringkali disebut jagat cilik. Bila manusia dapat menguasai dunia kecil ini, yakni dirinya sendiri, maka dia telah menjadi seorang ksatria pinandita, seorang raja pahlawan merangkap pendeta. Dalam dirinya sendiri telah tercapai kesatuan, seperti batinnya mempunyai asal-usul Ilahi, demikianpun badannya mengalami proses spiritualisasi, berkembang menjadi roh Ilahi dan telah dimulai suatu perkembangan harmonis."

Berdasar pada konsep tersebut, manusia Jawa memiliki empat kepercayaan, sebagaimana disebut oleh Pujiyanto (2010: 9-10) berikut:

a. Kepercayaan terhadap kekuatan gaib (supranatural). Segala sesuatu yang ada di bumi ini adalah bernyawa (mempunyai roh) dan dipercayai bahwa yang bernyawa memiliki kekuatan sakti atau daya gaib, bahkan di luar alam raya ada alam lain yang merupakan tempat kehidupan makluk halus. Makluk halus itu biasa hidup melekat di benda dan ruangan yang dianggap sakral. 
b. Kepercayaan terhadap arwah. Sistem kepercayaan adanya roh jelmaan dari tokoh-tokoh leluhur yang sakti. Roh jelmaan tersebut dipercayai tetap memiliki kesaktian dan dapat dimintai tolong untuk mendatangkan kemuliaan dan keselamatan hidupnya.

c. Kepercayaan terhadap Dewa Raja. Raja dianggap titisan dari Dewa yang ditugaskan mengendalikan kekuat an alam. Raja adalah pemimpin, penuntun, panutan, sekaligus guru bagi kawulanya demi kesejahteraan hidup manusia. Raja dianggap orang yang serba bisa (mumpuni) dan mengerti segala hal yang berhubungan dengan tugasnya (ngerti saliring reh).

d. Kepercayaan terhadap Tuhan. Kepercayaan terhadap sang Pencipta semesta alam.

Sejalan dengan pandangan tersebut, manusia Jawa cenderung memiliki watak dan tingkah laku sebagai berikut (Pujiyanto, 2010:11, Herusatoto, 1984:78-81).

a. Rila atau rela, yaitu keiklasan hati sewaktu menyerahkan segala miliknya, kekuasaan, dan seluruh hasil karyanya kepada Tuhan.

b. Narima atau menerima nasib yang diterimanya, yaitu ketenteraman di hati, mensyukuri nasibnya dan apapun yang diperolehnya.

c. Temen atau setia pada janji, yaitu menepati janji yang diucapkan, baik yang sudah diucapkan melalui bibirnya maupun diucapkan di dalam hatinya.

d. Sabar atau lapang dada, yaitu kuat terhadap segala cobaan dan tidak putus asa.

e. Budi luhur atau memiliki budi yang baik, yaitu suka menolong serta melindungi dengan tanpa mengharapkan balas jasa, seperti sifat yang dimiliki oleh Tuhan Yang Maha Esa.

Dalam perwujudan Batik Solo, simbolisasi yang digunakan manusia Jawa merupakan kesadaran yang terbentuk dan terungkap melalui tata ragam hias, tata warna, maupun totalitasnya. Manusia Jawa memiliki panduan petunjuk arah yang disebut dengan konsep Pajupat. Konsep tersebut begitu terkait pada kisah-kisah penciptaan dunia oleh Sang Pencipta. Menurut Endraswara (dalam Pitana, 2010: 134-135) bahwa pada mulanya di dunia hanyalah Tuhan. Sebelum dunia terbentuk, telah ada suara terlebih dahulu, yaitu suara gaib. Kemudian diciptakan cahaya rukyati (cahaya kehidupan), dan cahaya inilah yang menciptakan anasir manusia berupa api, bumi, air, dan laut. Dari api dijadikan nafsu, tanah dijadikan badan, angin dijadikan napas, air dijadikan roh. Arah (kiblat) alam semesta diawali dari arah Timur. Arah Timur adalah awal kiblat, sebagai 
simbol saudara manusia yang disebut kawah. Selanjutnya, menyusul Selatan sebagai simbol darah, Barat sebagai simbol pusar (plasenta), dan Utara simbol adhi ari-ari (adik ari-ari/plasenta). Pemahaman mengenai penciptaan dunia tersebut menghasilkan keyakinan bahwa dunia ini diciptakan Tuhan untuk manusia agar hidup manusia selamat. Tuhan telah memberikan petunjuk arah yang dijadikan empat unsur yang diyakini sebagai saudara kembar manusia. Saudara manusia tersebut diyakini bahwa lahir pada hari yang sama, tetapi berbeda tempat. Keempat arah kiblat oleh orang Jawa senantiasa disatukan dan diseimbangkan karena apabila hubungan dengan keempat saudara tersebut dibina secara seimbang maka pancer (manusia yang terlahir) dapat dibantu oleh keempatnya.

Sejalan dengan hal tersebut, dalam perwujudan Batik Solo terdapat ajaranajaran dalam kehidupan manusia atas kosmologinya yang harus dibaca. Apabila melihat tata ragam hias dan warna, maka muncul unsur-unsur yang terkandung di dalamnya. Unsur-unsur yang dikandung dalam kain Batik Solo dapat diungkapkan dari dua sisi, yaitu: 1) hubungan antara warna dan mata angin; dan 2) warna dan komponen ragam hias (ornamen), yang berakar pada papat keblat kalima pancer (empat mata angin) Susanto (1973: 173, 283) mengungkapkan kedua hubungan tersebut sebagai berikut.

a. Timur disesuaikan dengan warna putih. Hal itu melambangkan unsur angin atau Maruta (udara), yang digambarkan dengan ornamen burung. Unsur ini akan berkembang menjadi watak "berbudi-bawa laksana" yaitu sifat adil dan berperikemanusiaan.

b. Selatan melambangkan warna merah. Hal itu melambangkan unsur Geni atau api, digambarkan dengan ornamen lidah-api. Bila tidak dikendalikan akan menjadi watak pemarah, bila dikendalikan akan menjadi watak pemberani dan pahlawan.

c. Barat melambangkan warna kuning. Hal itu melambangkan unsur Banyu atau air, yang digambarkan dengan ornamen ular atau ikan. Bila tidak dikendalikan, maka akan berkembang ke arah sifat pembohong, tetapi bila dikendalikan akan menjadi sifat jujur dan kesatria.

d. Utara melambangkan warna hitam (biru tua). Hal itu melambangkan unsur bumi, yang digambarkan dengan ornamen Meru. Jika tidak dikendalikan akan mendorong sifat angkara-murka, tetapi bila dikendalikan akan menjadi sifat kesentausaan abadi. Ajaran Islam sangat menekankan adanya hubungan pakaian dan ibadah, seperti yang tertera dalam hadis berikut ini.

"Ada dua golongan penghuni neraka yang aku belum pernah melihatnya:

Laki-laki yang tangan mereka menggenggam cambuk yang mirip ekor sapi 
untuk memukuli orang lain dan wanita-wanita yang berpakaian namun telanjang dan berlenggak-lenggok. Kepalanya bergoyang-goyang bak punuk onta. Mereka itu tidak masuk surga dan tidak pula mencium baunya. Padahal sesungguhnya bau surga itu bisa tercium dari jarak sekian dan sekian" (HR. Muslim).

Dari Hadis itu, dipahami bahwa orang yang tidak berpakaian dengan rapi akan masuk neraka. Batik yang panjang dan lebar, dirasa cukup untuk menutup aurat.

Keempat arah tersebut juga dimaknai sebagai proses kehidupan manusia dalam menjalani sangkan paraning dumadi, yaitu: 1) timur merupakan arah awal kehidupan/kelahiran; 2) selatan merupakan arah kedewasaan; 3) barat merupakan arah kematangan; dan 4) utara merupakan arah kematian (Pujiyanto, 2010:72). Unsur-unsur yang dilambangkan dengan bermacam ornamen dalam perwujudan Batik Solo tersebut juga mengekspresikan ajaran hidup manusia Jawa yang mencerminkan ajaran Manunggaling Kawula Gusti (lihat Gambar IV.16).

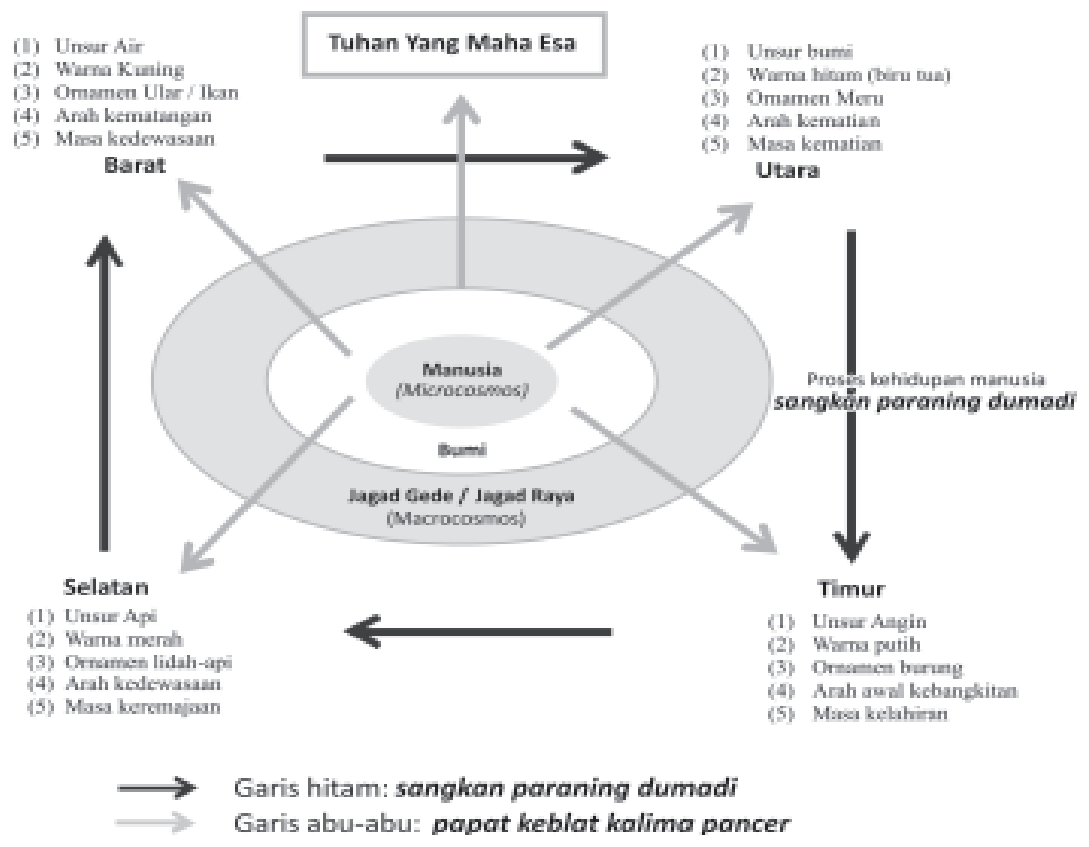

Gambar IV.16: Skema sangkan paraning dumadi dan papat keblat kalima pancer dalam kosmologi manusia Jawa

(pengembangan dari Pitana, 2010:136 dan Pujiyanto, 2010:70)

(1): unsur, (2): warna, (3) ornamen, (4): arti arah, (5) tahap manusia 


\section{Batik Solo sebagai Ekspresi Daur Hidup Manusia Islam Jawa}

Batik Solo bukan sesuatu yang hanya indah secara visual, tetapi juga sesuatu yang diberi makna atau arti di dalamnya, baik melalui ragam hias maupun warna yang erat hubungannya dengan falsafah hidup para penciptanya. Ragam hias dalam Batik Solo telah diciptakan dengan pesan dan harapan yang tulus dan luhur yang diharapkan mampu membawa kebaikan serta kebahagiaan bagi si pemakainya. Harapan ini semua dilukiskan secara simbolis, bahkan hal ini merupakan ciri khas Batik Solo (Djoemena, 1990a: 10).

Batik Solo bukanlah semata-mata wujud karya ilmu rancang seni yang dianggap sebagai seni halus, tetapi sekaligus memiliki fungsi sebagai busana manusia Jawa yang dipakai dalam kegiatan daur hidup manusia Jawa terutama oleh kalangan keraton. Daur hidup adalah siklus hidup manusia. Siklus ini diartikan bahwa proses yang dijalani manusia sejak saat masih berada di kandungan ibu hingga saat meninggal dunia ini. Widiastuti (2011a: 2) berpendapat bahwa ada tiga fase yang penting dalam daur hidup manusia, yakni kelahiran, perkawinan, dan kematian.

Keterkaitan batik dengan daur hidup manusia ini dapat diamati dari peristiwa-peristiwa berikut (Prawiroharjo, 2011:7-9).

a. Pada saat orang Jawa lahir di dunia ini, mereka ditemani kain batik untuk menjauhkan bayi yang baru lahir dari segala kejahatan.

b. Pada saat meninggal dunia, jenazahnya ditutupi dengan sehelai kain batik dengan doa agar selamat perjalanannya serta harapan bahagia yang abadi di alam akhirat.

Jenis kain Batik Solo yang digunakan dalam upacara yang berkaitan dengan daur hidup tersebut dapat dijelaskan, sebagai berikut.

Pertama, upacara yang berkaitan dengan kelahiran, kain batik yang beragam-hias seperti, Sidomukti, Sidoluhur, Sidohasih, Sidomulyo, Sidodadi, Semen Rama, Wahyu Tumurun, dan Babon Angrem digunakan dalam upacara Mitoni. Upacara tersebut diadakan pada saat umur kandungan ibu sudah mencapai tujuh bulan. Dalam upacara ini, selamatan diharapkan agar proses kelahiran nantinya berjalan lancar, tepat pada waktunya, tidak prematur, dan tidak terlalu lama di kandungan. Sebagai bagian dari ritual yang dijalani, ibu yang sedang hamil dioles pada tujuh bagian tubuhnya (muka, dada, punggung, kedua tangan, dan kedua kaki) dengan tujuh macam boreh (campuran daundaun obat). Selain itu, tujuh jenis kain Batik Solo dipakaikan secara bergantian. Maksud dari ritual ini untuk menolak bala at as bayi yang dikandungnya dan mendatangkan pengaruh yang baik pada kehidupan nantinya. Masih upacara 
yang berkaitan dengan kelahiran, yaitu upacara Brokohan. Kain batik yang digunakan yaitu beragam-hias, seperti Kawung, Parang, Truntum, dan Cakar. Sementara itu, kain batik yang beragam-hias, seperti Sidomukti, Sidoluhur, Semen Rama, dan Wahyu Tumurun digunakan dalam upacara Puput Puser. Upacara Brokohan diadakan pada saat bayi lahir serta upacara Puput Puser (upacara penanaman ari-ari) diadakan pada saat tali ari-ari bayi putus, kemudian ari-ari ditanam yaitu dikembalikan ke tanah. Dalam acara ini, selamatan diartikan bahwa anak yang baru lahir dapat tumbuh dengan selamat menjadi besar tanpa ada halangan (Suyono, 2007: 135-140, Widiastuti, 2011a: 4-10 dan 2011b: 2-3).

Kedua, upacara yang berkaitan dengan perkawinan. Kain batik beragamhias Semen Rama, Satrio Wibowo, Wahyu Tumurun, dan Truntum digunakan dalam upacara Midodareni. Upacara Midodareni dilaksanakan pada malam sebelum perkawinan. Pengantin putri ditemani dengan saudara-saudara dan sahabat-sahabatnya sebagai acara perpisahan dengan masa remaja. Sementara itu, kain batik yang beragam-hias Sidoluhur, Sidoasih, dan Sidomulyo digunakan dalam upacara Akad Nikah/janji pernikahan (dalam agama Islam disebut Ijab Qobul, dalam agama Kristen disebut Sakramen Perkawinan) dan dalam upacara Panggih Temanten. Upacara Akad nikah adalah upacara pernyataan perkawinan antarpengantin putra dan putri. Pada upacara ini, mempelai putra dengan mempelai putri mengucapkan janji seumur hidup. Akad nikah dilaksanakan sesuai dengan keyakinan agama masing-masing. Upacara Panggih Temanten adalah upacara pertemuan antara pengantin putra dan putri yang dilaksanakan setelah upacara akad nikah. Pada upacara ini, kedua pengantin bertemu secara resmi di depan tamu (Hariwijaya, 2004:97-172, Herusatoto, 1984:109-111, Widiastuti, 2011 a: 4-10 dan 2011b: 3).

Ketiga, upacara yang berkaitan dengan kematian. Kain batik yang digunakan dalam upacara kematian, seperti Kawung, Slobog atau kain batik yang dicintai oleh almarhum semasa hidupnya. Dalam masyarakat Jawa terdapat suatu keyakinan hidup setelah mati. Dengan demikian, mati bukan akhir kehidupan melainkan awal dari kehidupan kekal. Roh keluarga yang telah lebih dahulu meninggal akan bertemu kembali kepada keluarganya dalam suasana kebahagiaan (Hariwijaya, 2004:97-172, Herusatoto, 1984:109-111, Widiastuti, 2011a:4-10, dan 2011b:3). 
Naomi Kawasaki: Religiositas Tradisi Jawa Islam dalam Seni Batik (hal. 174-186)

Tabel IV.1 Ragam Hias Batik Solo dalam Upacara Daur Hidup

\begin{tabular}{|c|c|c|}
\hline & Jenis upacara & Ragam Hias \\
\hline \multirow[t]{3}{*}{ Kelahiran } & Mitoni & $\begin{array}{l}\text { Sidomukti, Sidohulur, Sidolasill, Sidomulyo, } \\
\text { Sidodadi, Semen Rama, } \\
\text { Wahyu Tumurun, Babon Angrem }\end{array}$ \\
\hline & Brokohan & Kawung, Parang, Truntum, Cakar \\
\hline & Puput Puser & $\begin{array}{l}\text { Sidomukti, Sidohuhr, Semen Rama, } \\
\text { Walyu Tumurun }\end{array}$ \\
\hline \multirow[t]{2}{*}{ Perkawinan } & Midodareni & $\begin{array}{l}\text { Semen Rama, Satrio Wibowo, } \\
\text { Walyu Tumurun, Truntum }\end{array}$ \\
\hline & Puput Puser & $\begin{array}{l}\text { Sidomukti, Sidoluhur, Semen Rama, } \\
\text { Wahyu Tumurun }\end{array}$ \\
\hline Kematian & & $\begin{array}{l}\text { Kawung, Slobog, } \\
\text { kain batik yang dicintai oleh almarhum semasa } \\
\text { hidupnya }\end{array}$ \\
\hline
\end{tabular}

\section{Simpulan}

Dalam daur hidup manusia Jawa, kain Batik Solo digunakan pada acara yang berhubungan dengan adat-istiadat Jawa yang disebut upacara "slametan (selamatan)". Upacara slametan menjadi kegiatan sosio-religius masyarakat Jawa. Ada tiga prosesi terkait dengan slametan, yakni kelahiran, pernikahan, dan kematian. Dengan adanya pemahaman mengenai batik yang memiliki sisi religius itulah, reformulasi Batik Solo sebagai karya adiluhung dapat terpelihara eksistensinya. Oleh karena itu, implementasi ragam hias Batik Solo bukan karena pengaruh permintaan pasar seperti yang terjadi dalam gelora modernitas. Batik Solo yang sesungguhnya adalah karya yang tetap memegang nilai luhur untuk prosesi ritual bagi kehidupan. Ragam hias pada batik tradisional Solo mengandung pesan dan harapan tulus yang diyakini akan membawa kebaikan dan kebahagiaan bagi Si pemakai. Batik tradisional Solo dapat dimaknai sebagai kain yang mengandung makna simbolis dalam ragam hiasnya, yang penggunaannya disesuaikan dengan kegiatan adat yang berlaku beserta suasana yang melingkupinya.

\section{Daftar Pustaka}

Atmojo, Heriyanto. 2008.Batik Tulis Tradisional Kawuman, Solo Pesona Budaya dan Eksotik. Solo: Penerbit Tiga Serangkai.

De Johng, S. 1984. Salah Satu Sikap Hidup Orang Jawa. Cetakan ke-4. Yogyakarta: Kanisius. 
Departemen Perindustrian Badan Penelitian dan Pengembangan Industri Balai Besar Penelitian dan Pengembangan Industri Kerajinan dan Batik Yogyakarta. 1986. Sejarah Industri Batik Indonesia. Yogyakarta. T.P. Djumena, Nian S.1990a. Ungkapan Sehelai Batik: It's Mystery and Meaning. Jakarta: Djambatan. 1990b. Batik dan Mitra. Jakarta: Djambatan.

Fashri, Fauzi. 2007. Penyingkapan Kuasa Simbol. Yogyakarta: Juxtapose. Hardjonagoro, Panembahan. 2001. Kirab Pusaka. Solo: Solo Murni.

Hariwijaya, M. 2008. Tata Cara Penyelenggaraan Perkawinan Adat Jawa. Cetakan ke-2. Yogyakarta: Hanggar Kreator.

Herusatoto, Budiono. 1984. Simbolisme dalam Budaya Jawa. Yogyakarta: PT. Hanindita.

Inagaki, Kazuko. 1976. A Study of Javanese Batik (Part 1) - History of Javanese Batik. Bulletin of the Facluty of Education Kobe University,Vol. 55 Jilid 30-Maret 1976, hal. 7-18.

1977. A Study of Javanese Batik (Part 2) - Use of Javanese Batik. Bulletin of the Faculty of Education Kobe University,Vol. 58 Jilid 30-September 1977, hal. 35-52.

Pitana, Titis S. 2001. "Javanese Cosmology and its Influence on Javanese Architecture: A Case Study of the Mataram King's Cemetery (Astana Imogiri)" dalam Tesis. Queensland: James Cook University. 2010. "Dekonstruksi Makna Simbolik Arsitektur Keraton Surakarta”. dalam Disertasi. Denpasar: Program Pascasarjana Universitas Udayana.

Widiastuti, Theresia. 1993. "Pergeseran pada Batik Surakarta" dalam Tesis. Bandung: Program Pascasarjana Institut Teknologi Bandung. 